\title{
Models of Care for Frail Older Adults
}

\author{
Mary Ersek, R.N., Ph.D., FAAN and Eeeseung Byun, R.N., M.S.N., ACNP-BC \\ University of Pennsylvania School of Nursing, Philadelphia, Pennsylvania, USA
}

The growth of the aging population in Korea will challenge health and social services. As Korean society changes, the U.S. models of end-of-life care and geriatric care for frail older adults may have increasing relevance for the Korean healthcare system. This article reviews three U.S. models of care for frail older adults: hospice and palliative care, the Program for All-Inclusive Care for the Elderly (PACE), and the transitional care model. We describe the strengths and limitations of each model and discuss ways in which these models could be adapted for the Korean healthcare system. (Korean J Hosp Palliat Care 2011;14:71-80)

Key Words: Palliative care, Organizational models, Geriatrics

\section{Introduction}

The aging population is burgeoning throughout the world, especially in developed countries. The percentage of those over 65 in Korea was 9\% in 2005, and is expected to rise to $38 \%$ by 2050 (1). The population of Korea is aging much faster than in other developed countries, and this explosive growth will challenge health care and social services in the near future.

Advances in healthcare and attention to healthy lifestyles promise to increase the proportion of healthy older adults. However, many older adults have multiple comorbidities, ill health, and require assistance in activities of daily living. Growing numbers of older adults may need care in a long-term care setting. For example, 23\% of older Americans have five or more chronic diseases (2). One concept that best describes this vulnerable population is frailty (3). The prevalence of frailty is $6.9 \%$ among older community-dwelling adults in the United States (3). Frailty is defined as the

Received on April 11, 2011. Revised on April 11, 2011.

Accepted on April 18, 2011.

Corresponding author: Mary Ersek

Tel: 215-746-3563, Fax: 215-573-7507

E-mail: ersekm@nursing.upenn.edu

This work was supported in part by the John A. Hartford Foundation Building Academic Geriatric Nursing Capacity Predoctoral Scholarship. "diminished capacity to withstand stress that places individuals at risk for adverse health outcomes" $(4,5)$. This clinical phenomenon is marked by several key features: weight loss, fatigue and poor endurance, lowered performance, and loss of physical strength. Presence of at least three of these core characteristics is associated with functional impairment, falls, hospitalization, and death (3-5). Frailty is progressive and often leads to increasing dependence on caregivers (4).

Eldercare in Korea typically has been provided by families, most often by female members of the household. Traditionally, women worked at home as housewives and one of their main roles included providing care for frail older adults. During the last half century, there have been remarkable changes in family structure in Korea. Compared to the past, more women are working outside the home and fewer older adults are living with their adult children. Moreover, Korea has a low birth rate, 1.22 in 2010 (6), and thus the proportion of the older adult population is also rapidly growing (1). Early retirement from paid employment has been a social issue in Korea that can add financial burden including medical costs. These social trends will add to the social and economic costs of eldercare in Korea.

Korean elder care in the future may be increasingly similar to that of the United States. For several decades, the nuclear family has been commonplace in the Unites States. When an aging parent's frailty or illness increases dependence on adult children, older adults often must leave their home and move 
closer to the adult child caregiver, sometimes into the caregiver's home. These changes can increase stress for older adults, caregivers, and caregivers' families. American women, who often assume primary caregiving responsibilities, find themselves "sandwiched" between the demands of caring for their ailing parent(s) and raising children. In the United States, approximately $66 \%$ of caregiving for family or friends is provided by women (7). These responsibilities frequently are added to the demands of a paid job or career. When adult children are unavailable for caregiving responsibilities, spouses may assume care for their partner. In these circumstances, the spouse caregiver may also be in poor health or have immune-system suppression (8-10). Caregiving stress is a risk factor for higher caregiver morbidity and mortality $(8,11,12)$. Common stress-related illnesses in caregivers include cardiovascular disease and depression (13-15).

The Korean healthcare system is still dependent on family caregivers to meet the increasing needs of an aging population. Lack of facilities and trained personnel for older adults may add burden to older adults themselves, to families, and to society. As Korean society changes, the U.S. models of end-of-life care for frail older adults may have increasing relevance for the Korean healthcare system. The purpose of this article is to review three U.S. models of care for frail older adults. We begin with a description of hospice and palliative care as is it commonly delivered in the United States. Despite its promise for ensuring patient-centered care that addresses families' and patients' needs and goals, hospice and palliative care models have shortcomings when applied to frail older adults. These limitations will be presented and discussed. Two other geriatric models, the Program for All-Inclusive Care for the Elderly (PACE) and the Transitional Care Model, offer features that can address the limitations. We will describe these advantages and provide a synthesis of key components for geriatric care at the end of life. We will conclude the paper with a discussion of how these models could be adapted for the Korean healthcare system.

\section{Hospice and Palliative Care}

As noted, frailty is progressive and is associated with increased morbidity and mortality. This trajectory fits with palliative care, which focuses on chronic, debilitating, and life-threatening illnesses (16). Palliative care is patient- and family centered; the goal is to enhance quality of life by preventing and treating suffering. Although its role increases as the illness progresses and the end-of-life approaches, palliative care is appropriate throughout the continuum of illness (Figure 1) (16).

Hospice is the oldest established palliative care program in the United States. The first U.S. hospice program started in the early 1970s. In 1982, hospice became a federally-financed (Medicare) healthcare benefit for persons 65 years and older, which spurred tremendous growth in this model of care. Hospice services focus on the last 6 months of life, and are usually provided in the home, long-term care facilities, and inpatient hospice units. Although hospice initially served mostly advanced cancer patients, now over $60 \%$ of U.S. hospice patients have noncancer diagnoses (17), including congestive heart failure, dementia, and pulmonary disease. In general, hospice patients choose comfort care rather than opting for aggressive, life-prolonging therapies.

In the years following the establishment of hospice, clinicians, researchers, and policymakers identified that many patients dying in nonhospice settings, especially hospitals, received burdensome, ineffective therapies aimed at prolonging life. Oftentimes, these situations occurred because providers failed to identify or discuss illness trajectories and goals of

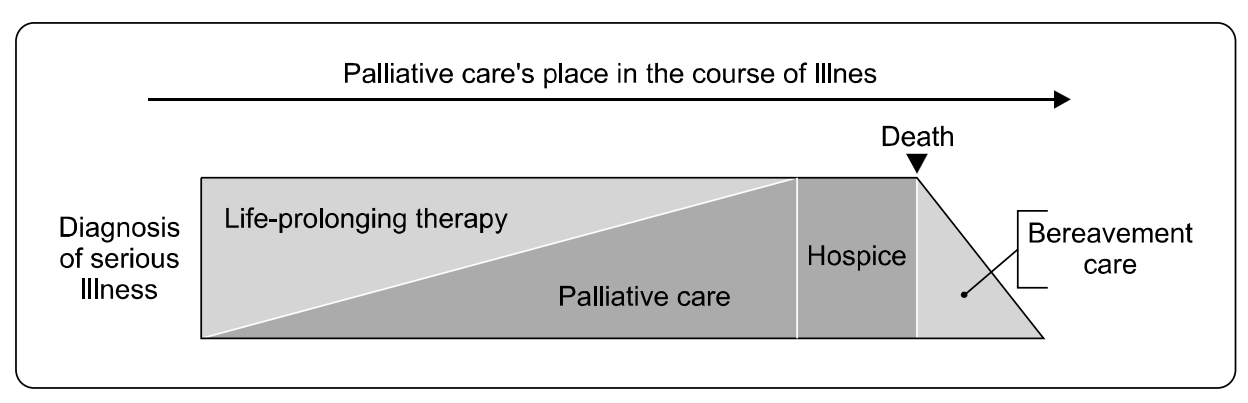

Figure 1. Model of palliative and hospice care. 
care with patients who had serious, progressive illness and their families. These patients were not receiving hospice care, either because their terminal condition went unrecognized or unacknowledged, or because they were not eligible for hospice. The unnecessary suffering and healthcare expenditures prompt- ed a movement to bring hospice "upstream" and allow patients access to palliative care services earlier in the disease course. The movement was marked by the growth of palliative care programs, largely in acute-care settings, and to a lesser extent, outpatient and community settings. Although

Table 1. Comparison of Palliative and Hospice Care.

\begin{tabular}{|c|c|c|}
\hline & Palliative care & Hospice \\
\hline Stage of illness & Throughout the course of progressive illness & Last 6 months of life \\
\hline Setting of care & $\begin{array}{l}\text { Any setting, but most palliative care services operate } \\
\text { in acute care }\end{array}$ & $\begin{array}{l}\text { Home, including long-term care facility, } \\
\text { inpatient hospice unit }\end{array}$ \\
\hline $\begin{array}{l}\text { Patient population(s) } \\
\text { served }\end{array}$ & $\begin{array}{l}\text { Serves patients with any progressive, life- limiting illness (e.g., } \\
\text { cardiovascular disease, neuromuscular diseases, dementia, COPD) }\end{array}$ & $\begin{array}{l}\text { Although hospice initially served mostly advanced } \\
\text { cancer patients, trend is for increasing numbers } \\
\text { of patients with non-cancer diagnoses }\end{array}$ \\
\hline $\begin{array}{l}\text { Use of curative } \\
\text { therapies }\end{array}$ & Allows for curative therapies as well as those aimed at comfort & $\begin{array}{l}\text { Patient chooses against aggressive therapies aimed } \\
\text { at cure }\end{array}$ \\
\hline Time frame & Not exclusively focused on end of life & Focused on the final six months of life \\
\hline
\end{tabular}

Table 2. Eight Domains of Palliative Care and Guidelines for Palliative Care Programs as Identified by the National Consensus Project (2009).

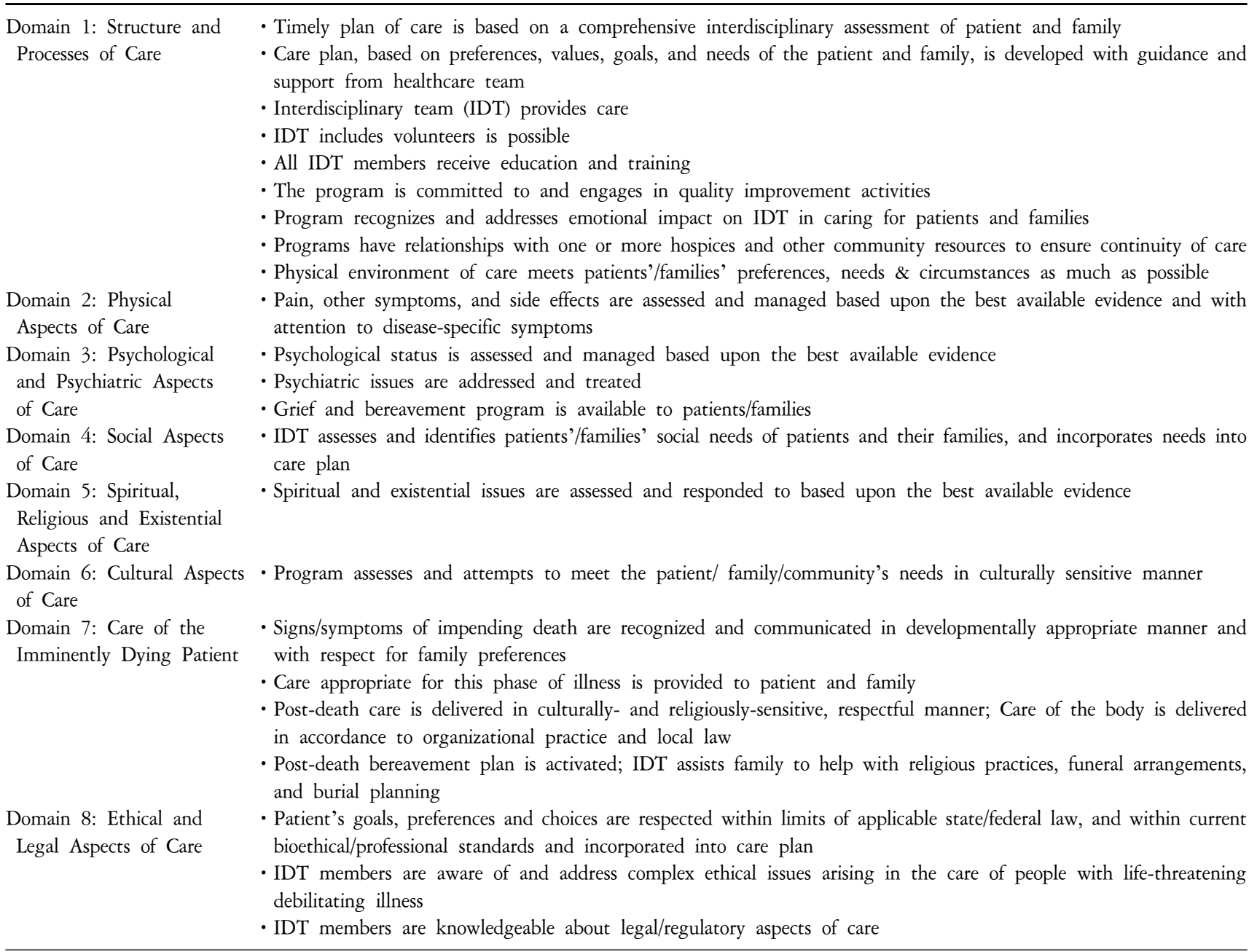


hospice and palliative care both serve persons with serious illness and their families, there are important distinctions between the two. In part these differences exist because of the varying strategies for financing these services. Table 1 outlines the basic distinctions between hospice and palliative care as they currently exist in the United States.

As of 2006 , more than $53 \%$ of U.S. hospitals with 50 or more beds had a palliative care program (18). Inpatient acutecare teams are by far the most common type of palliative care program. The interdisciplinary team (IDT) serves as a consultation team on fixed-bed units, swing-bed units, and scatter-beds. Outpatient palliative care programs are found in ambulatory-care settings; these services are typically limited to Monday through Friday, 8 AM to 5 PM (or a few days a week). Some do provide weekend/night on-call services for their patients. Community palliative care programs often collaborate with hospice or home-health agencies to support seriously ill patients who have not yet accessed or are eligible for hospice. A handful of palliative care programs exist in nursing homes and other long-term care settings.

Because there was no unifying funding mechanism, as there is with hospice, each palliative care program is unique to its healthcare organization, and each team's composition, expertise, and range of services vary considerably. In part to address the lack of uniformity, a group of leading hospice and palliative care organizations joined together to identify core components of palliative care programs, and to develop and disseminate guidelines under the umbrella of the National Consensus Project for Quality Palliative Care (NCP). In 2004, the NCP published Clinical Practice Guidelines for Quality Palliative Care, and a revised, second edition was released in 2009. These guidelines have been used to guide policymakers, providers, practitioners, and consumers in understanding the principles and practices of quality palliative care (19). The NCP described eight domains of palliative care with accompanying recommendations and standards for care. These domains are outlined in Table 2.

Despite the tremendous growth of hospice and palliative care, barriers to providing focused, high-quality care to persons with serious, life-limiting illness still exist. These barriers include consumers' and clinicians' lack of knowledge about the availability and scope of these services. In many cases, unwillingness or inability to talk about poor prognosis and eventual death prevents referrals to hospice and palliative care. Vast health disparities in the U.S. also contribute to the problem. Because many Americans worry about having access to the full range of curative therapies and tertiary services, hospice and palliative care often are seen as "lesser" services in which the goal is to save money rather than deliver high-level care focused on the patient's quality of life, goals, and values.

\section{Strengths and Challenges of the Palliative Care Approach for Frail Older Adults}

Palliative care has many features that make this approach ideal for frail older adults (Table 3). These include a focus on patient and family goals and explicit attention to emotional, spiritual, and cultural aspects of care. IDT members are specifically trained to communicate effectively and sensitively with patients and families about difficult issues. There is an explicit attention to loss, grief, and bereavement, which are universal experiences in the lives of frail older adults and their families. In addition, hospice care is a widely available healthcare benefit. In 2009, almost $42 \%$ of Americans who died received hospice services at some point in their illness (17). Thus, increasing numbers of Americans are familiar with

Table 3. Strengths and Challenges of U.S. Palliative Care as a Model of Care for Frail Older Adults.

\begin{tabular}{ll}
\hline \multicolumn{1}{c}{ Strengths } & Challenges \\
\hline Focus on patient \& family goals & $\begin{array}{c}\text { Most palliative care teams serve frail older adults by default, not by } \\
\text { design; thus, palliative care teams' knowledge of geriatric syndromes } \\
\text { and care may be quite limited } \\
\text { No consistent model of palliative care delivery expect for hospice } \\
\text { Explicit attention to emotional, spiritual, and cultural aspects of care } \\
\text { IDT members are specifically trained to communicate effectively }\end{array}$ \\
$\begin{array}{l}\text { Ond sensitively with patients and families about difficult issues } \\
\text { Explicit attention to loss, grief and bereavement rather than a primary care service } \\
\text { Hospice care is well established. Hospice and palliative care more }\end{array}$ & $\begin{array}{l}\text { Reimbursement structure for palliative care not always clear } \\
\text { Although care coordination across settings is a goal, many palliative } \\
\text { widely available than other two models }\end{array}$ \\
\hline
\end{tabular}


hospice care; the accessibility and uniformity of the services available under the hospice benefit help to drive its popularity.

Despite these advantages, palliative care does not universally address all the major needs of this population (Table 3). Although the majority of U.S. decedents each year are 65 years and older, most palliative care teams serve frail older adults by default, not by design. Depending on the treatment setting, many IDT members' knowledge of geriatric syndromes and care is limited. Moreover, there is no consistent model of care delivery outside of hospice. Although there are guidelines for palliative care, many teams do not have the resources to meet the standards. Recently the Joint Commission, a not-for-profit organization that accredits and certifies healthcare organizations and programs in the U.S. and around the world, announced an Advanced Certification Program for Palliative Care (20). Although this certification is voluntary, it represents a step forward in standardizing services. Another challenge with the current palliative care model is that IDT members usually serve in a consultant role, thereby limiting their ability to ensure continuity of care and integration of palliative care approaches into the overall care plan. Finally, the reimbursement structure for palliative care is not always clear, which may limit the ability of a palliative care team in providing comprehensive services across settings.

\section{Program of All-Inclusive Care for the Elderly}

The Program of All-Inclusive Care for the Elderly (PACE), now a national model of care, was first initiated in the early 1970s in San Francisco California's Chinatown as a community-based long term care program providing primary care and social services using a team. The PACE model provides a comprehensive set of preventive, primary, acute, and longterm care services. PACE offers an alternative to nursing home care, allowing elders to remain in the community. The core component of the PACE model is the integration of the IDT team and social support services with bundled payment from Medicare and Medicaid. Currently, there are currently 75 PACE programs across the United States (21). PACE is funded through a capitated payment system, meaning that the program receives a set monthly payment from federal and state funding sources (i.e., Medicare and Medicaid) to cover all the care for its enrollees (21).
To be eligible for enrollment in a PACE program an individual must be 55 years or older, live in a PACE service area, be certified by the state to need nursing home-level care, and be able to live at home with PACE services at the time of enrollment (21). The average PACE participant is 80 years old ( $74 \%$ are 75 or older; more than $33 \%$ are 85 or older), female $(75 \%)$ and has 7.9 medical conditions (most of which are chronic conditions) (22). Because of dual Medicare/Medicaid eligibility, PACE tends to serve lower-income older adults (21). The PACE model is centered in a day-care setting where program members can receive nursing care, social services, occupational therapy, physical therapy, nutrition, recreational activities, personal care, and transportation to and from the program. All services are approved by the IDT. Members receive primary care and other health care services that may include rehabilitation, audiology, dentistry, optometry, podiatry, and specialty services. PACE care covers hospitalizations, emergency care, medications, durable medical equipment, and clinical diagnostic services.

The outcomes of the PACE Model are impressive. PACE members have lower skilled home-health visits, experience fewer hospitalizations, and have fewer nursing-home admissions. Overall, PACE members have increased survival rates, increased numbers of days in the community, better health and functional status, better quality of life, and greater satisfaction with care (23-26).

PACE addresses several challenges in the palliative care model: focus on frail older adults, knowledge of geriatric care, and consistent care by the interdisciplinary care team. The PACE team serves as the member's primary-care team, promoting an integrated approach to care, and allows continuity of care across settings. The team model incorporates physical, mental, and psychosocial aspects of care.

Some challenges with this model include the limited accessibility of a PACE program in many locales. This is because starting and managing a PACE program is challenging; for example, the infrastructure necessary to support the program is complex, there often is a lack of qualified care providers and administrators, and there may be insufficient numbers of enrollees in a given geographic area. From a palliative care perspective, the model does not specifically focus on identifying members' and families' goals for end-oflife care. 


\section{Transitional Care Model}

Two primary models of transitional care have been developed and tested in the United States. Eric Coleman, MD, MPH developed a model known as the Care Transitions Program and Mary Naylor, $\mathrm{PhD}, \mathrm{RN}, \mathrm{FAAN}$ is nationally known for the Transitional Care Model. Transitional care is defined "as a set of actions designed to ensure the coordination and continuity of health care as patients transfer between different locations or different levels of care within the same location" (27). Frail older adults often need complex care from different healthcare providers in a same location or in multiple settings (28). In a complex healthcare delivery system, older adults are transferred from between settings, especially in and out of acute care settings. As a result, they may experience poor care coordination or low quality of care (28). The transitional care model aims to improve care for frail older adults with multiple comorbidity and risk factors during transitions within and between settings, and prevents unnecessary rehospitalization.

Like palliative care, the transitional care model is patientand family-caregiver focused. Working collaboratively with older adults, their caregivers, and with healthcare team members (e.g., physicians and physical therapists) across settings (e.g., hospital, home, and skilled nursing facility), an advanced practice nurse (APN) with advanced skills in gerontology assures continuity of care. Ensuring this continuity of care is especially important in the United States, which does not have an integrated healthcare system.
Transitional care is distinguished from other models of health care in that care is delivered and coordinated by the same APN in hospitals, skilled nursing facilities, and homes, seven days per week, using an evidence-based protocol with focus on long-term outcomes. The essential elements of the transitional care model are explained in Table 4 (29). The emphasis is on screening and symptom management, and patient/family education to promote health self-management.

Implementation of the transitional care model has been shown to decrease short-term (6-week) and longer-term (6and 12-month) hospital readmissions after discharge, and decrease healthcare costs (30-32). In addition, transitional care can improve short-term quality of life and increase patient satisfaction (30).

The transitional care model addresses the lack of continuity of care that often can increase older persons' vulnerability to poor outcomes. Although the APNs ensure high-quality care for older adults and follow them across settings, this model does not include an entire team. Other disadvantages are the limited availability of transitional care programs and the lack of a standard financing mechanism to pay for this care.

\section{Discussion}

This paper describes three U.S. approaches to address the complex healthcare and social needs of frail older adults. Common features of the three models include patient- and family-centered care, care delivered by an IDT, and delivery of care that has demonstrated effectiveness to enhance patient outcomes and minimize unnecessary healthcare costs. Care

Table 4. Ten Essential Elements of the Transitional Care Model [http://www.transitionalcare.info].

1. The advanced practice nurse (APN), a master's prepared nurse with advanced knowledge and skills in the care of older adults, as the primary coordinator of care to ensure consistency of health care provider across the entire episode of care

2. In-hospital assessment, collaboration with team members to decrease adverse events and prevent functional decline, and development of an evidenced-based plan of care

3. Regular home visits by the APN with continuous telephone support ( 7 days per week) through an average of 2 months post discharge

4. Continuity of medical care between hospital and primary care physicians facilitated by the APN accompanying patients to follow-up visits with physicians

5. Comprehensive focus on individual patient's needs (e.g. reason for the primary hospitalization, comorbidity and risks)

6. Active engagement of patients and their family caregivers including education and support

7. Emphasis on early identification and response to health care risks and symptoms to achieve longer-term positive outcomes and avoid adverse events contributing to rehospitalization

8. Multidisciplinary approach that includes the patient, family caregivers and health care providers as part of a team

9. Physician-nurse collaboration

10. Communication to, between and among the patient, family caregivers and health care providers 
coordination and reduction of transitions between healthcare settings are core goals of all three models. Although palliative care, PACE and transitions models have proven success, each has limitations in scope of services and accessibility.

Given the current state and future direction of caring for frail older adults in Korea, lessons from each of the three U.S. care-delivery models can be applied to Korean services for the aging. Ideally, future services for frail older adults will incorporate end-of-life care, as well as geriatric care models to current clinical practice.

In Korea, the National Cancer Center developed a standardized hospice and palliative care education program for healthcare providers with financial support from the Ministry of Health, Welfare, and Family during 2006 2008 (33). The demonstration program was performed and preliminary results have shown that the program was successful (33). Further development of this education system and applying it nationally to current clinical practice are required. Training IDTs specializing in palliative and hospice care, as well as reimbursement for care from national health insurance, will improve the quality of end-of-life care in Korea.

The process to change policies will likely be a long journey in Korea because of legal, ethical, economic, and cultural factors. Lack of understanding about the philosophy and goals of end-of-life care is problematic in Korea. For example, both healthcare providers and patients have concerns about addiction to pain medications, and both groups are reluctant to use opioids analgesics for cancer patients (34). These attitudes are a major obstacle for effective symptom management and palliative care. Additional consumer and clinician education about appropriate end-of-life care is needed.

Another challenge to providing hospice and palliative care in Korea is the current practice that limits these services to cancer patients. Instead, this care model should be offered to patients with other debilitating diseases, such as heart disease, stroke or HIV/AIDS. Persons with any life-limiting illness need management for physical symptoms and psychosocial distress. For instance, patients with stroke may have pain from muscle contracture or hemiplegia or experience poststroke depression. Families may need to be involved in decision making for withdrawal of care in some cases where stroke patients are diagnosed with brain death or will not recover from stroke. Thus, excellent symptom management and decision-making support should not be limited to cancer patients and their families.

Another barrier to caring for frail elders using a palliative care model concerns issues around advance directives. Despite technological advances in healthcare, patients' rights to refuse treatment at end of life have only recently been recognized in Korea (35). Making healthcare decisions is difficult because "do not resuscitate" (DNR) designations are not allowed by law (35). Reflection and consideration of what older adults want for their end-of-life care would help terminally ill patients and their families prepare to have a "good death."

Because life expectancy has increased in Korea, both the formal care system and informal networks, including family members, need to share in the responsibility of caregiving for older adults. Adapting or applying a PACE program or transitional care model may improve quality of care for frail older adults in Korea. As expected, there will be challenges to applying these U.S. models in Korea. Starting a PACE program in Korea would carry enormous costs. However, community healthcare centers known as Bogunso, may be able to adapt and apply the PACE model to provide IDT care and services for frail older adults.

The transitional care model is important to ensuring high quality care for older adults as they move from one setting to another. Adopting this model would require the design and implementation of a reimbursement system and specialized training programs for APNs and other healthcare providers.

The role of APNs is important in all three models of care. Defining the role and standardizing education for APNs at the master's level in Korea is in the early stages. There are presently few APNs, and they are primarily available in university teaching hospitals. The role and scope of practice of these APNs varies depending on the hospital. A standardized scope of practice will need to be defined for licensing purposes, as will policies of reimbursement for APN practice by national health insurance. Nonetheless, ample evidence from U.S. studies of palliative care, transitional care, and the PACE model demonstrate many advantages to APN-delivered healthcare services.

\section{Conclusions}

Examining various U.S. models can aid in the development 
of standardized geriatric and end-of-life care for older adults in Korea. Modifying each model to best fit the culture, values, and healthcare delivery system in Korea is important to the success of this process, as is a cultural shift to embrace the viewpoints and opinions of individual patients and their families. Education efforts must not be addressed only to healthcare providers, but also to older adults, families, and communities.

\section{Acknowledgements}

The authors want to express their appreciation to Eileen Sullivan-Marx, PhD, CRNP, RN, FAAN and Pamela Z Cacchione, PhD, APRN, GNP, BC for their review and comments on the Program of All-Inclusive Care for the Elderly model.

\section{References}

1. Howe N, Jackson R, Nakashima K. The aging of Korea: demographics and retirement policyin the land of the morning calm. Washington, DC:Center for Strategic and International Studies;2007.

2. Anderson GF. Medicare and chronic conditions. N Engl J Med 2005;353(3):305-9.

3. Fried LP, Tangen CM, Walston J, Newman AB, Hirsch C, Gottdiener $\mathrm{J}$, et al. Frailty in older adults: evidence for a phenotype. J Gerontol A Biol Sci Med Sci 2001;56(3):M146-56.

4. Boockvar KS, Meier DE. Palliative care for frail older adults: "there are things I can't do anymore that I wish I could...". JAMA 2006;296(18):2245-53.

5. Fried LP, Ferrucci L, Darer J, Williamson JD, Anderson G. Untangling the concepts of disability, frailty, and comorbidity: implications for improved targeting and care. J Gerontol A Biol Sci Med Sci 2004;59(3):255-63.

6. kosis.kr [Internet]. Daejeon: Korean Statistical Information Service; c2010 [cited 2011 Mar 28]. Available from: http://www. kosis.kr/.

7. Caregiving in the U.S. 2009 [Internet]. Bethesda: National Alliance for Caregiving in collaboration with AARP; c2009 [updated 2009; cited 2011 Feb 21. Available from: http://www. caregiving.org/data/Caregiving_in_the_US_2009_full_report.pdf.

8. Schulz R, Beach SR. Caregiving as a risk factor for mortality: the Caregiver Health Effects Study. JAMA 1999;282(23):2215-9.

9. Vitaliano PP, Zhang J, Scanlan JM. Is caregiving hazardous to one's physical health? A meta-analysis. Psychol Bull 2003;129(6): 946-72.
10. Bauer ME, Vedhara K, Perks P, Wilcock GK, Lightman SL, Shanks N. Chronic stress in caregivers of dementia patients is associated with reduced lymphocyte sensitivity to glucocorticoids. J Neuroimmunol 2000;103(1):84-92.

11. Haley WE, Roth DL, Howard G, Safford MM. Caregiving strain and estimated risk for stroke and coronary heart disease among spouse caregivers: differential effects by race and sex. Stroke 2010;41(2):331-6.

12. Lee S, Colditz GA, Berkman LF, Kawachi I. Caregiving and risk of coronary heart disease in U.S. women: a prospective study. Am J Prev Med 2003;24(2):113-9.

13. White CL, Mayo N, Hanley JA, Wood-Dauphinee S. Evolution of the caregiving experience in the initial 2 years following stroke. Res Nurs Health 2003;26(3):177-89.

14. Berg A, Palomäki $\mathrm{H}$, Lehtihalmes $\mathrm{M}$, Lönnqvist J, Kaste $\mathrm{M}$. Poststroke depression: an 18-month follow-up. Stroke 2003;34(1): $138-43$.

15. Berg A, Palomäki H, Lönnqvist J, Lehtihalmes M, Kaste M. Depression among caregivers of stroke survivors. Stroke 2005; 36(3):639-43.

16. National Consensus Project for Quality Palliative Care. Clinical practice guidelines for quality palliative care [Internet]. 2nd ed. Pittsburgh, PA: National Consensus Project for Quality Palliative Care; c2009 [updated 2009; cited 2011 Apr 9]; p. 1-80. Available from http://www.nationalconsensusproject.org/guideline. pdf.

17. National Hospice and Palliative Care Organization. NHPCO facts and figures: hospice care in America [Internet]. 2010 edition. Alexandria, VA: National Hospice and Palliative Care Organization; c2010 [cited 2011 Apr 9]; p. 1-15. Available from http:// www.nhpco.org/files/public/Statistics_Research/Hospice_Facts_Figur es_Oct-2010.pdf.

18. Center to Advance Palliative Care. America's care of serious illness: a state-by-state report card on access to palliative care in our nation's hospitals [Internet]. New York: Center to Advance Palliative Care; c2008 [cited 2011 Apr 9]; p. 1-36. Available from http://www.capc.org/reportcard/state-by-state-report-card.pdf.

19. The National Consensus Project for Quality Palliative Care [Internet]. Pittsburgh, PA: National Consensus Project; c20042011 [cited 2010 Nov 18]. Available from http://www.nationalconsensusproject.org/.

20. Advanced certification for palliative care programs [Internet]. Oakbrook Terrace, IL: The Joint Commission; c2011 [cited 2011 Apr 9]. Available from http://www.jointcommission.org/certification/palliative_care.aspx.

21. npaonline.org [Internet]. Alexandria, Virginia: National PACE Association; c2002 [cited 2011 Apr 11]. Available from http:// www.npaonline.org.

22. Mukamel DB, Temkin-Greener H, Clark ML. Stability of disability among PACE enrollees: financial and programmatic implications. Health Care Financ Rev 1998;19(3):83-100. 
23. Friedman SM, Steinwachs DM, Rathouz PJ, Burton LC, Mukamel DB. Characteristics predicting nursing home admission in the program of all-inclusive care for elderly people. Gerontologist 2005;45(2):157-66.

24. Mukamel DB, Temkin-Greener H, Delavan R, Peterson DR, Gross D, Kunitz S, et al. Team performance and risk-adjusted health outcomes in the Program of All-Inclusive Care for the Elderly (PACE). Gerontologist 2006;46(2):227-37.

25. Temkin-Greener H, Mukamel DB. Predicting place of death in the program of all-inclusive care for the elderly (PACE): participant versus program characteristics. J Am Geriatr Soc 2002;50(1):125-35.

26. Grabowski DC. The cost-effectiveness of noninstitutional longterm care services: review and synthesis of the most recent evidence. Med Care Res Rev 2006;63(1):3-28.

27. Coleman EA, Boult C; American Geriatrics Society Health Care Systems Committee. Improving the quality of transitional care for persons with complex care needs. J Am Geriatr Soc 2003;51(4): 556-7.

28. Coleman EA. Falling through the cracks: challenges and opportunities for improving transitional care for persons with continuous complex care needs. J Am Geriatr Soc 2003;51(4): 549-55.

29. Transitional care model: key elments [Internet]. Philadelphia, PA: Transitional care model; c2008-2009. [cited 2011 Apr 9]. Avail- able from http://www.transitionalcare.info//AbouKeyE-1804.html.

30. Naylor MD, Brooten DA, Campbell RL, Maislin G, McCauley KM, Schwartz JS. Transitional care of older adults hospitalized with heart failure: a randomized, controlled trial. J Am Geriatr Soc. 2004;52(5):675-84.

31. Naylor MD, Brooten D, Campbell R, Jacobsen BS, Mezey MD, Pauly MV, et al. Comprehensive discharge planning and home follow-up of hospitalized elders: a randomized clinical trial. JAMA 1999;281(7):613-20.

32. Naylor MD, Brooten D, Jones R, Lavizzo-Mourey R, Mezey M, Pauly M. Comprehensive discharge planning for the hospitalized elderly. A randomized clinical trial. Ann Intern Med 1994; 120(12):999-1006.

33. Kang J, Koh SJ, Yoo YS, Choi YS, Choi JY, Chang YJ, et al. Development of the standard hospice and palliative care education program in Korea: results from the demonstration project. J Palliat Med 2010;13(6):703-10.

34. Kim SH, Choi YS, Shin SW, Chong MK, Lee SN, Lee SW, et al. Development of education program for physicians based on the 2004 hospice palliative model project for terminal cancer. Korean J Hosp Palliat Care 2006;9:67-76.

35. Kim DY, Lee KE, Nam EM, Lee HR, Lee KW, Kim JH, et al. Do-not-resuscitate orders for terminal patients with cancer in teaching hospitals of Korea. J Palliat Med 2007;10(5):1153-8. 